\title{
Matriz porosa do BV60S associada a células osteoprogenitoras alógenas no tratamento de defeitos ósseos críticos em rádios de cães
}

[Porous matrix of BG60S associated with allogenic osteoprogenitor cells in the treatment
of critical bone defects in the radius of dogs]

E.G.L. Alves1,2

https://orcid.org/0000-0001-8524-3949

R. Serakides 2 ,

https://orcid.org/01 https://orcid.org/0000-0001-7819-4253

F.N. Machado2,

E.G.L. Alves ${ }^{1,2}$, R. Serakides ${ }^{2}$, I.R. Rosado ${ }^{1,2}$, F.N. Machado ${ }^{2}$, F.B. Fukushima ${ }^{2}$, M.M. Pereira ${ }^{2}$, A.M. Góes ${ }^{2}$, C.M.F. Rezende ${ }^{2}$

${ }^{1}$ Universidade de Uberaba - Uberaba, MG

${ }^{2}$ Universidade Federal de Minas Gerais - Belo Horizonte, MG

https://orcid.org/000 https://orcid.org/0000-0001-9843-8374 M.M. Pereira2,

https://orcid.org/0000-0001-8867-682X A.M. Góes2,

https://orcid.org/0000-0002-0262-949X C.M.F. Rezende2

RESUMO

O objetivo do estudo foi avaliar o efeito da matriz porosa do biovidro 60S (BV60S) associada a células osteoprogenitoras (CO) alógenas no tratamento de defeitos ósseos críticos de cães. Foram utilizados 20 cães, machos, sem raça definida, com dois anos de idade e massa corporal média de $25 \mathrm{~kg}$. Com os cães sob anestesia geral, foram criados defeitos ósseos críticos no terço médio dos ossos rádios. Procedeu-se à fixação óssea com uma placa em ponte, e os defeitos foram tratados de acordo com cada grupo experimental. Constituíram-se três grupos experimentais, em que os defeitos ósseos foram preenchidos com: BV60S associado a CO alógenas (grupo BV60S+CO), osso autógeno (grupo C+), ou não preenchidos (grupo C-). A regeneração óssea foi avaliada por meio de exames radiográficos, densitométricos e histomorfométricos ao longo de 90 dias. Os grupos C- e BV60S+CO mostraram preenchimento ósseo parcial do defeito de, no máximo, 56,68\% e 35,23\%, respectivamente, sem a formação de ponte óssea entre as extremidades, e o controle positivo $(\mathrm{C}+)$ mostrou regeneração óssea completa. Conclui-se que a matriz porosa do BV60S associada às células osteoprogenitoras não é eficiente no tratamento de defeitos ósseos críticos em rádios de cães.

Palavras-chave: regeneração óssea, ortopedia, terapia celular, biomateriais

\begin{abstract}
The objective of this study was to evaluate the effect of the porous matrix of bioglass 60S (BV60S) associated with allogenic osteoprogenitor cells $(\mathrm{CO})$ in the treatment of critical bone defects of dogs. 20 male mongrel dogs at two years old and mean weight of $25 \mathrm{~kg}$ were used. Dogs were anesthetized and critical bone defects were created in the middle third of the radios bones. With dogs under general anesthesia, critical bone defects were created in the middle third of bone radios. Bone fixation was done with a bridge plate and defects treated according to each experimental group. Three experimental groups were formed according to the treatment. The defects filled with BV60S associated with allogenic CO (Group-BV60S+CO), autogenous bone (Group-C+) or unfilled (Group-C-). Bone regeneration was evaluated by radiography, bone densitometry and histomorphometry over 90 days. The BV60S+CO and $C$ - groups showed partial bone filling of the defect of at most $56.68 \%$ and $35.23 \%$, respectively. No bone bridge formation was observed between the extremities in the BV60S+CO and $C$ - groups. Positive control showed complete bone regeneration at 90 days. It was concluded that the porous matrix of BV60S associated with osteoprogenitor cells was not effective in the treatment of critical bone defects in the radius of dogs.
\end{abstract}

Keywords: bone regeneration, orthopedics, cell therapy, biomaterials

Recebido em 23 de fevereiro de 2018

Aceito em 3 de janeiro de 2019

E-mail: endrigoglalves@gmail.com 


\section{INTRODUÇÃO}

O tratamento de defeitos ósseos críticos ainda é um dos maiores desafios da ortopedia veterinária e da humana. O autoenxerto é considerado a melhor alternativa para o tratamento desses defeitos, mas algumas limitações, como maior tempo cirúrgico, complicações no local da colheita, fragilização do local e a quantidade limitada de osso coletado, estão associadas a esse tipo de enxertia (DeCamp et al., 2015). Devido a isso, muito se tem estudado em busca de alternativas eficientes para substituição dessa forma de enxertia, e a produção de matrizes sintéticas advindas de biomateriais parece ser a alternativa mais viável e promissora (Alves et al., 2015a). Os biovidros são considerados os mais ativos e favoráveis à regeneração óssea (Coelho et al., 2005). O biovidro 60S (BV60S) de composição molar $4 \% \mathrm{P}_{2} \mathrm{O}_{5} ; 36 \% \mathrm{CaO} ; 60 \%$ $\mathrm{SiO}_{2}$ já mostrou efeitos benéficos na regeneração óssea in vitro, favorecendo a atividade biológica de osteoblastos caninos (Alves et al., 2015b) e aumentando a osteogênese durante o processo de diferenciação osteogênica de células-tronco mesenquimais de cães (Alves et al., 2015c). Além disso, pode ser associado a células osteoprogenitoras, capazes de sintetizar matriz extracelular, regenerando o defeito ósseo. Estudos já mostraram que o uso de células osteoprogenitoras alógenas é viável (Arinzeh et al., 2003; Alves et al., 2017a) e permite o tratamento de forma imediata, utilizando-se células criopreservadas. Desse modo, o objetivo do presente estudo foi avaliar a matriz porosa do biovidro de composição molar $60 \% \mathrm{SiO} 2,36 \%$ $\mathrm{CaO}, 4 \%$ P2O5 (BV60S), associada a células osteoprogenitoras alógenas, no tratamento de defeitos ósseos críticos em rádios de cães.

\section{MATERIAL E MÉTODOS}

Este estudo foi realizado de acordo com as normas internacionais de bem-estar animal, após aprovação pelo Comitê de Ética em Experimentação Animal da UFMG (protocolo $\mathrm{n}^{\circ}$ 157/2009). A matriz porosa do BV60S foi produzida de acordo com protocolo estabelecido por Coelho e Pereira (2005), utilizando-se $133,8 \mathrm{~mL}$ de tetraetilortosilicato (TEOS), $13,6 \mathrm{~mL}$ de trietilfosfato (TEP), $97,9 \mathrm{~mL}$ de água deionizada $16,3 \mathrm{~mL}$ de solução de ácido nítrico $2 \mathrm{~N}$ e $85,01 \mathrm{~g}$ de nitrato de cálcio $\left[\mathrm{Ca}\left(\mathrm{NO}_{3}\right)_{2}\right.$ $4 \mathrm{H}_{2} \mathrm{O}$ ]. Foi utilizado $1 \mathrm{~mL}$ de surfactante para cada $80 \mathrm{~mL}$ de solução. A catalisação da reação foi realizada com $4 \mathrm{~mL}$ de ácido fluorídrico (HF) $10 \%$ para cada $100 \mathrm{~mL}$ da solução final. A solução foi aerada com o auxílio de batedeira elétrica. Espuma do BV60S foi acondicionada em recipiente de polipropileno de forma cilíndrica com $2 \mathrm{~cm}$ de diâmetro e $3 \mathrm{~cm}$ de altura. $\mathrm{O}$ biovidro foi submetido à secagem em estufa, $\mathrm{a}$ $60^{\circ} \mathrm{C}$ por 72 horas, seguindo-se um aumento gradual da temperatura em $10^{\circ} \mathrm{C}$ a cada 24 horas, até se atingir a temperatura de $120^{\circ} \mathrm{C}$. As amostras foram tratadas termicamente na mufla a $700^{\circ} \mathrm{C}$ por seis horas. As amostras foram embaladas separadamente e esterilizadas por radiação gama.

A porosidade total da matriz do biovidro $60 \mathrm{~S}$ foi calculada pela seguinte fórmula:

porosidade total

$(\%)=\left(\frac{\text { densidade verdadeira-densidade volumétrica }}{\text { densidade verdadeira }}\right) \times 100$, em que: a densidade verdadeira foi medida por picnometria de Hélio $\left(2,7 \mathrm{~g} / \mathrm{cm}^{3}\right)$ e a densidade volumétrica foi calculada dividindo-se a massa da matriz $(\mathrm{g})$ pelo seu volume $\left(\mathrm{cm}^{3}\right)$.

Para análise morfológica da estrutura porosa, as matrizes foram recobertas com carbono (SPI/Supplies-EUA) e analisadas por microscopia eletrônica de varredura (MEV-FEIInspect-S50/República Tcheca).

A obtenção das células osteoprogenitoras (CO) foi realizada de acordo com Alves et al., (2017b), utilizando-se três cães, machos, sem raça definida, com dois anos de idade e peso médio $18 \mathrm{~kg}$. Colheu-se $1 \mathrm{~cm}^{3}$ de tecido adiposo de cada animal na região subcutânea glútea. As amostras foram fragmentadas e submetidas à ação da colagenase (Colagenase B, Roche, Alemanha) $0,1 \% \quad \mathrm{P} / \mathrm{V}$ durante 45 minutos a $37^{\circ} \mathrm{C}$. Centrifugou-se a amostra por 10 minutos a 1400rpm; o sobrenadante contendo a fração adiposa foi descartado e o pellet, fração estromal, foi ressuspenso em $20 \mathrm{~mL}$ de meio de cultura (meio basal), DMEM com baixa glicose, enriquecido com gentamicina $(60 \mu \mathrm{g} / \mathrm{L})$, penicilina $(100 \mathrm{UI} / \mathrm{mL})$, estreptomicina $(100 \mu \mathrm{g} / \mathrm{mL})$, anfotericina $(25 \mu \mathrm{g} / \mathrm{mL})$ e $10 \%$ de soro fetal bovino. As células foram cultivadas até atingirem 80 a $90 \%$ de confluência e foram, então, repicadas. Após o terceiro repique, as células foram avaliadas quanto à viabilidade 
celular pelo azul de Tripan, plaqueadas na densidade de $1 \times 10^{4}$ células $/ \mathrm{cm}^{2}$ e cultivadas com meio osteogênico constituído do meio basal enriquecido com ácido ascórbico $(50 \mu \mathrm{g} / \mathrm{mL})$, Bglicerofosfato $(10 \mathrm{mM})$ e dexametasona $(0,1 \mu \mathrm{M})$. Em seguida, as células foram cultivadas a $37^{\circ} \mathrm{C}$ e $5 \%$ de $\mathrm{CO}_{2}$ por 21 dias para diferenciação osteogênica. Transcorrido esse período, as células foram utilizadas para o tratamento de defeitos ósseos associadas à matriz porosa do biovidro $60 \mathrm{~S}$, na densidade $3 \times 10^{6}$ células por $\mathrm{cm}^{3}$ de defeito, assim como o utilizado por Arinzeh et al. (2003) e Alves et al. (2017a).

Para comprovação da diferenciação osteogênica após 21 dias de cultivo, realizou-se a quantificação relativa dos transcriptos gênicos para osterix (OSX), sialoproteína óssea (BSP) e osteocalcina (OC) por RT-PCR, em tempo real, pelo método $2^{-\Delta \Delta C T}$. As reações de RT-PCR foram realizadas, utilizando-se $2 \mu \mathrm{g}$ de cDNA, $5 \mathrm{pM}$ de cada iniciador e $12,5 \mu \mathrm{L}$ do reagente Sybr Green (SuperScript ${ }^{\mathrm{TM}}$ III Platinum ${ }^{\circledR}$ TwoStep qRT-PCR Kit with SYBR Green, Invitrogen, CA, USA), em um volume final de $25 \mu \mathrm{L}$ de reação em um poço, no aparelho SmartCycler System. Os parâmetros utilizados para amplificação foram: $50^{\circ} \mathrm{C}$ por 120 segundos, $95^{\circ} \mathrm{C}$ por 150 segundos e 45 ciclos, $95^{\circ} \mathrm{C}$ por 15 segundos e $60^{\circ} \mathrm{C}$ por 30 segundos. Foram utilizados os primers F- ACGACACTGGGCAAAGCAG e RCATGTCCAGGGAGGTGTAGAC para OSX, F- TTGCTCAGCATTTTGGGAAT e RAACGTGGCCGATACTTAAAGAC para BSP e F- GAGGGCAGCGAGGTGGTGAG e RTCAGCCAGCTCGTCACAGTTGG para OC. $\mathrm{O}$ gene gliceraldeído-3-fosfato desidrogenase (GAPDH) foi utilizado como normalizador da reação com os primers F-CCATCTTCCAGGAGCGAGGAT e RTTCTCCATGGTGGTGAAGAC. O osteoblasto canino foi utilizado com padrão de expressão dos transcriptos. A formação de nódulos de mineralização foi avaliada pela coloração de Von Kossa (Alves et al., 2015c).

Para criação dos defeitos ósseos críticos e tratamento com matriz porosa do BV60 associada às $\mathrm{CO}$, utilizaram-se 20 cães hígidos, machos, sem raça definida, com dois anos de idade e massa corporal média de $25 \mathrm{~kg}$. Os cães foram aleatoriamente distribuídos em dois grupos experimentais: grupo controle negativo
(C-) - animais com defeitos ósseos críticos sem preenchimento $(\mathrm{n}=10)$ e grupo $\mathrm{BV60S}+\mathrm{CO}-$ animais com defeitos ósseos críticos tratados com matriz porosa do BV60S associada a células osteoprogenitoras $(n=10)$. O controle positivo (C+) foi realizado em todos os animais utilizando-se o rádio contralateral, com defeito crítico preenchido com o próprio fragmento ósseo retirado da ostectomia.

Para realização das cirurgias, os cães receberam, como medicação pré-anestésica, atropina 0,02mg/kg SC (Pasmodex, Isofarma, Brasil) e, 10 minutos após, acepromazina $0,03 \mathrm{mg} / \mathrm{kg}$ IM (Acepran 0,2\%, Vetnil, Brasil) e morfina 0,8mg/kg IM (Dimorf, Cristália, Brasil). A indução anestésica foi realizada com propofol $3 \mathrm{mg} / \mathrm{kg}$ IV (Fresofol, Fresenius Kabi, Brasil) e diazepam 0,3mg/kg IV (Diazepam, União Química, Brasil), seguindo-se a intubação endotraqueal e manutenção anestésica por meio da inalação espontânea de isoflurano (Isoforine, Cristália, Brasil) diluído em oxigênio puro. Para controle da dor e inflamação, foram administrados tramadol $3 \mathrm{mg} / \mathrm{kg}$ SC TID (Cloridrato de Tramadol, Teuto, Brasil) e meloxicam 0,2mg/kg IM SID (Maxicam injetável 0,2\%, Ouro Fino, Brasil) durante cinco dias consecutivos, bem como antibioticoterapia com cefalexina $(30 \mathrm{mg} / \mathrm{kg}$ VO, BID) durante sete dias consecutivos. O defeito ósseo crítico foi criado de acordo com Alves et al. (2015a), retirando-se um fragmento ósseo do terço médio do rádio com extensão correspondente a $1,5 \mathrm{vez}$ o diâmetro do osso. A estabilização óssea foi realizada com uma placa de aço F318 em ponte, posicionada na superfície cranial do rádio e fixada com seis parafusos. Após a fixação óssea, o defeito foi tratado de acordo com cada grupo experimental.

As avaliações radiográficas foram realizadas nas projeções radiográficas mediolateral e craniocaudal de ambos os rádios no pré e pósoperatórios imediatos e aos $15,30,45,60,75$ e 90 dias após a intervenção cirúrgica. A projeção craniocaudal foi utilizada para monitoração do alinhamento ósseo e a projeção mediolateral, para mensuração das áreas de crescimento ósseo nas linhas de osteotomia. As mensurações foram realizadas com auxílio do software Digimizer Image Analysis. As áreas correspondentes ao crescimento ósseo foram expressas em percentagem em relação à área total da falha 
óssea de cada animal considerada 100\% (Alves et al., 2015a; Alves et al., 2017a).

As avaliações densitométricas e histológicas foram realizadas em cinco animais de cada grupo aos 45 e 90 dias de pós-operatório. Para isso, os animais foram submetidos à eutanásia por meio da aplicação de propofol até parada cardiorrespiratória, seguida da injeção de $40 \mathrm{~mL}$ de cloreto de potássio. Os rádios e as ulnas foram dissecados, colhidos e fixados em formalina tamponada $10 \%$ por 30 dias. A avaliação densitométrica foi realizada utilizando-se um densitômetro de dupla emissão de raios $\mathrm{X}$ (Densitômetro DXA, modelo DPX-Alpha Lunar). A densidade mineral óssea $\left(\mathrm{g} / \mathrm{cm}^{2}\right)$ foi mensurada na região correspondente às falhas ósseas com incidência na projeção mediolateral. Os valores de densidade obtidos de cada falha foram convertidos em percentagem da densidade óssea normal do rádio de cada animal, considerada $100 \%$. A densidade óssea considerada normal foi obtida na região correspondente aos defeitos tratados com o autoenxerto (controle +) (Alves et al., 2015a; Alves et al., 2017a).

Para avaliação histológica e histomorfométrica, os rádios e as ulnas foram transversalmente seccionados na altura dos parafusos adjacentes à falha. O segmento ósseo central, contendo a falha, foi submetido ao protocolo de desmineralização com solução aquosa de ácido fórmico $50 \% \mathrm{~V} / \mathrm{V}$ e citrato de sódio $9 \% \mathrm{P} / \mathrm{V}$ por 90 dias. Após esse período, foi realizada uma secção longitudinal do segmento ósseo correspondente à falha $\mathrm{e}$ as metades foram processadas pela técnica rotineira de inclusão em parafina. Cortes histológicos de $5 \mu \mathrm{m}$ foram obtidos de cada bloco e corados pela técnica da hematoxilina-eosina. As lâminas foram avaliadas descritivamente por microscopia óptica. A área de neoformação óssea foi quantificada com o auxílio de uma ocular micrométrica, contendo uma gratícula com 121 pontos e com objetiva de $4 \times$ percorrendo-se toda a extensão do defeito. A área de neoformação óssea foi expressa em relação à área total do defeito de cada animal (Alves et al., 2015a; Alves et al., 2017a).
Foi utilizado delineamento inteiramente ao acaso com controle positivo pareado. Os dados foram submetidos à análise de variância (ANOVA), e as médias comparadas pelo teste StudentNewman-Keuls (SNK) utilizando o programa Graphpad Instat 3. Diferenças foram consideradas significativas se $\mathrm{P}<0,05$.

\section{RESULTADOS}

A matriz do BV60S apresentou porosidade média de $97,46 \%$, variando de 97,01 a $97,8 \%$. A microscopia eletrônica mostrou que a matriz apresentava poros interconectados com diâmetro médio de $507 \mu \mathrm{m}$, variando de 300 a $700 \mu \mathrm{m}$. Após 21 dias de cultivo em meio osteogênico, as células formaram nódulos de mineralização e aumentaram a expressão relativa dos transcriptos gênicos para osterix (5,94 vezes), sialoproteína óssea (20,48 vezes) e osteocalcina (32,51 vezes) em relação a células não diferenciadas.

O controle negativo (C-) e o grupo BV60S+CO mostraram preenchimento ósseo parcial do defeito de, no máximo, $56,68 \%$ e $35,23 \%$, respectivamente, sem a formação de ponte óssea entre as extremidades, e o controle positivo $(\mathrm{C}+)$ mostrou regeneração óssea completa em todos os animais aos 90 dias (Fig. 1). As áreas de preenchimento ósseo nos grupos C- e $\mathrm{BV} 60 \mathrm{~S}+\mathrm{CO}$ foram significativamente inferiores ao controle positivo $(\mathrm{C}+)$ em todos os tempos (Fig. 2).

Houve um preenchimento progressivo do defeito, com crescimento ósseo das extremidades em direção ao centro do defeito ósseo até o $75^{\circ}$ dia e uma subsequente redução da área de preenchimento ósseo no período seguinte (90 dias), em todos os grupos estudados (Fig. 2).

A área correspondente ao biomaterial mostrou rápida reabsorção após sua implantação, com redução média de $13,17 \%$ a cada 15 dias. A matriz porosa do BV60S foi completamente reabsorvida em $60 \%$ dos animais aos 90 dias. 


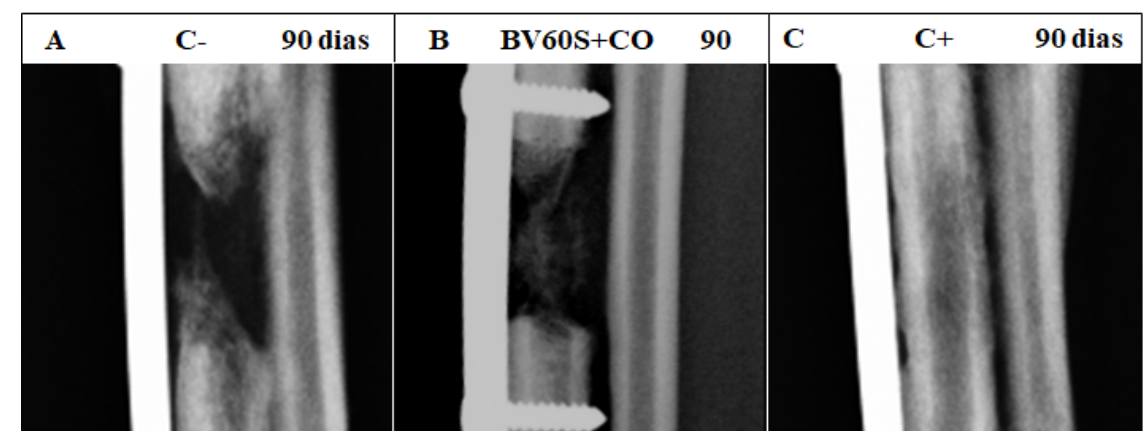

Figura 1. Imagens radiográficas de defeitos ósseos críticos em rádios de cães não tratados (A), tratados com matriz porosa de BV60S associada a CO (B) e osso autógeno (C), obtidas aos 90 dias de pósoperatório. Observar nas imagens A e B o preenchimento parcial do defeito com osso esponjoso das extremidades em direção ao centro do defeito.

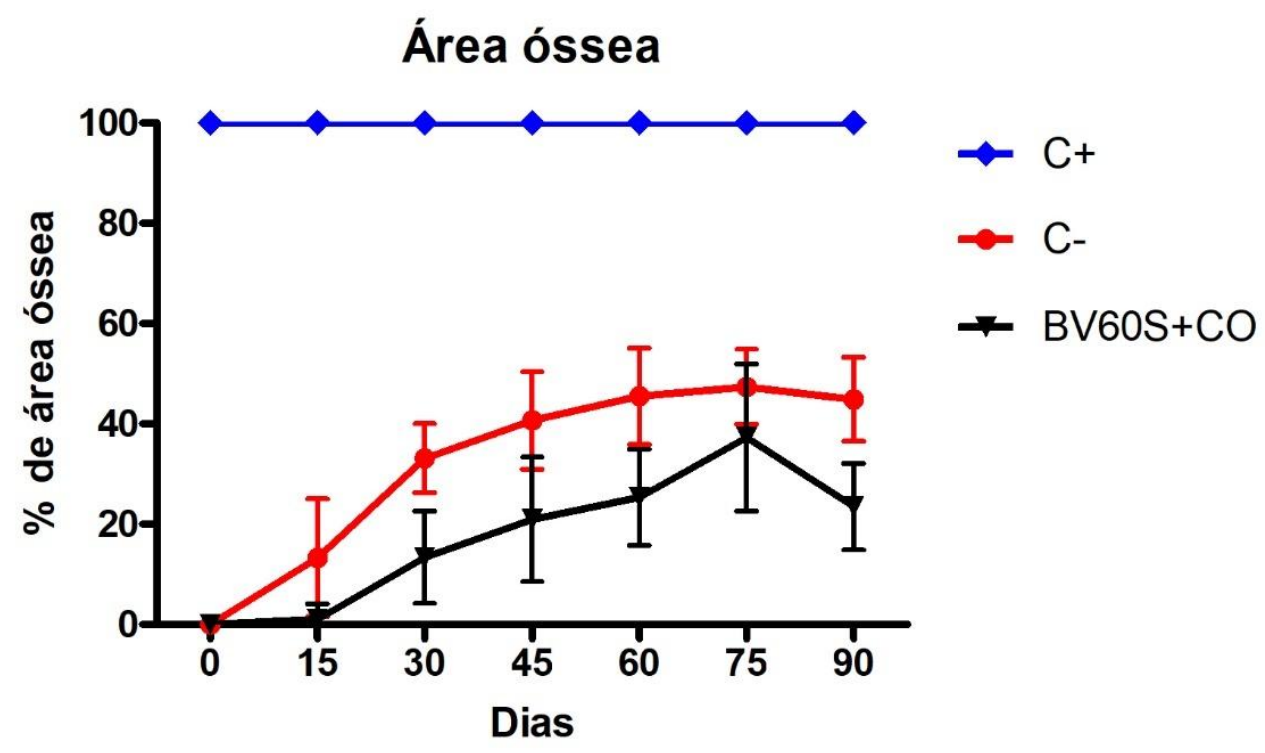

Figura 2. Percentagem média e desvio-padrão da área de preenchimento ósseo em defeitos críticos de rádios de cães, não tratados (C-), tratados com matriz porosa de BV60S associada a células osteoprogenitoras (BV60S+CO) e osso autógeno $(\mathrm{C}+)$, ao longo de 90 dias de avaliação pós-operatória (medidas obtidas radiograficamente).

Os grupos BV60S+CO e C- apresentaram menor densidade na região do defeito ósseo em relação ao controle positivo $(\mathrm{C}+$ ), aos 45 e 90 dias (Fig. $3)$. Aos 45 dias, o grupo BV60S+CO mostrou densidade superior ao grupo controle negativo (C-) e, aos 90 dias, nenhuma diferença foi observada entre os grupos C- e BV60S+CO (Fig. 3).

A avaliação histológica dos grupos controle negativo (C-) e tratados com matriz porosa de
BV60S associada a células osteoprogenitoras (BV60S+CO) mostrou neoformação óssea das extremidades do defeito em direção ao centro, sem união entre elas. O osso neoformado em todos os defeitos dos grupos C- e BV60 foi esponjoso, com trabéculas espessas (Fig. 4) predominantemente recobertas por osteoblastos volumosos. Verificou-se também uma predominância de osteócitos ativos em lacunas alargadas. 
Densitometria 45 dias

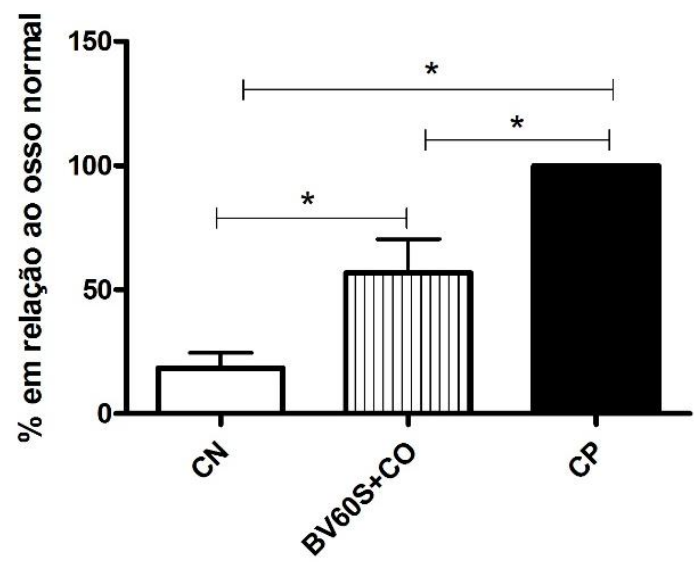

Densitometria 90 dias

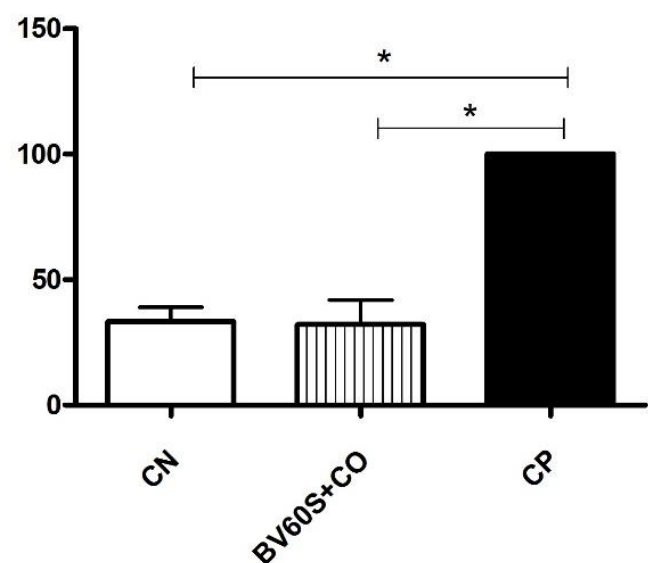

Figura 3. Densidade média e desvio-padrão de defeitos ósseos críticos em rádios de cães, não tratados (C-), tratados com matriz porosa de BV60S associada a células osteoprogenitoras (BV60S+CO) e osso autógeno $(\mathrm{C}+)$, aos 45 e 90 dias de pós-operatório. A densidade está expressa em percentagem em relação à densidade normal do rádio de cada animal. $*(\mathrm{P}<0,05)$.

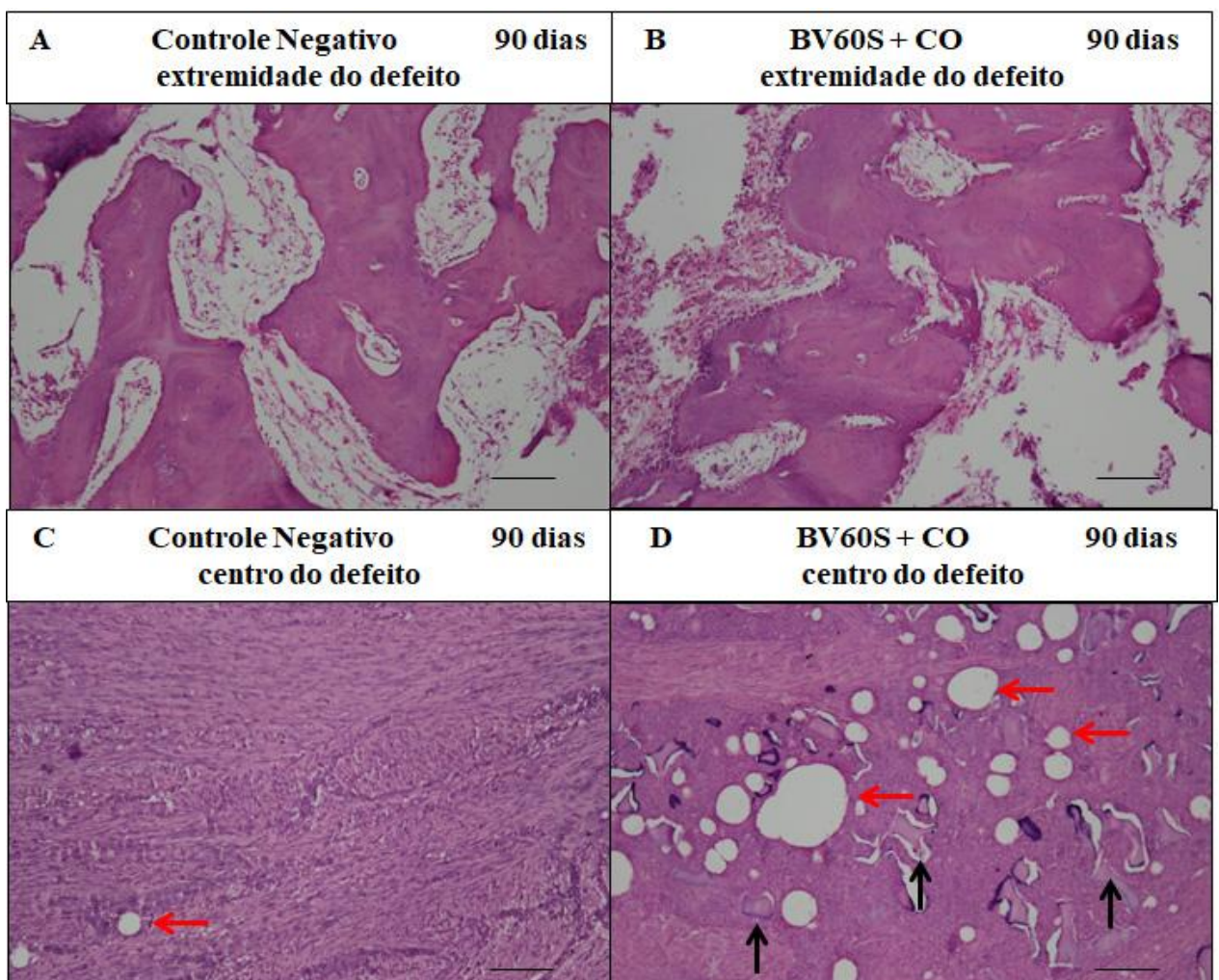

Figura 4. Micrografia dos tecidos ósseo (A e B) e conjuntivo fibroso (C e D) localizados, respectivamente, na extremidade e no centro de defeitos ósseos críticos em rádios de cães, não tratados (C-) e tratados com matriz porosa de BV60S associada a células osteoprogenitoras (BV60S+CO), aos 45 e 90 dias de pós-operatório. As setas pretas apontam fragmentos do BV60S, e as vermelhas vasos saguíneos. Hematoxilina-eosina. Barra $=93 \mu \mathrm{m}$. 
Verificou-se, pela avaliação histomorfométrica, aos 45 e 90 dias, que as áreas de neoformação óssea nos grupos C- e BV60S+CO foram significativamente inferiores ao $\mathrm{C}+\mathrm{A}$ neoformação óssea foi maior no grupo Cquando comparada à do grupo BV60S, em todos os tempos avaliados (Fig. 5). A média de desvio-

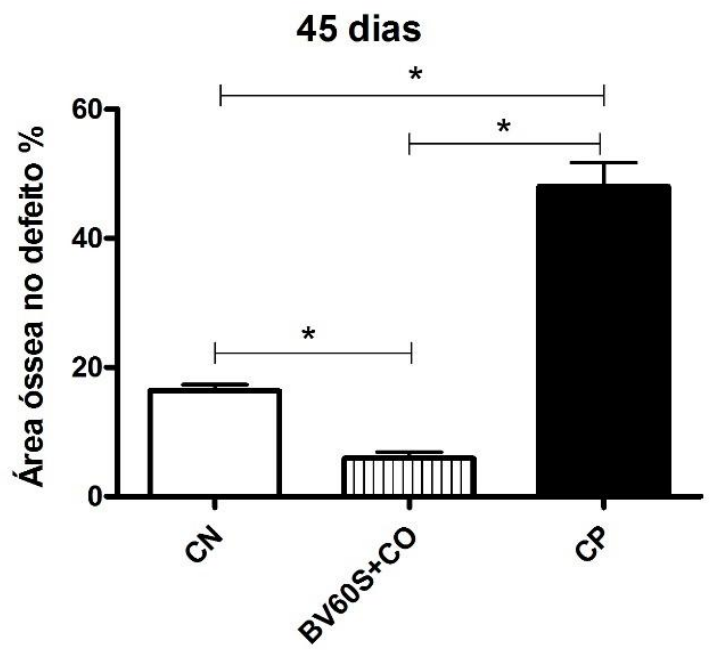

padrão do número de vasos por campo no centro do defeito dos grupos C- e BV60S+CO foi, respectivamente, $1,72( \pm 0,09)$ e $3,16( \pm 1,01)$, aos 45 dias, e $1,99( \pm 0,97)$ e $8,15( \pm 2,69)$, aos 90 dias, mostrando maior neovascularização do grupo BV60S+CO (Fig. 4).

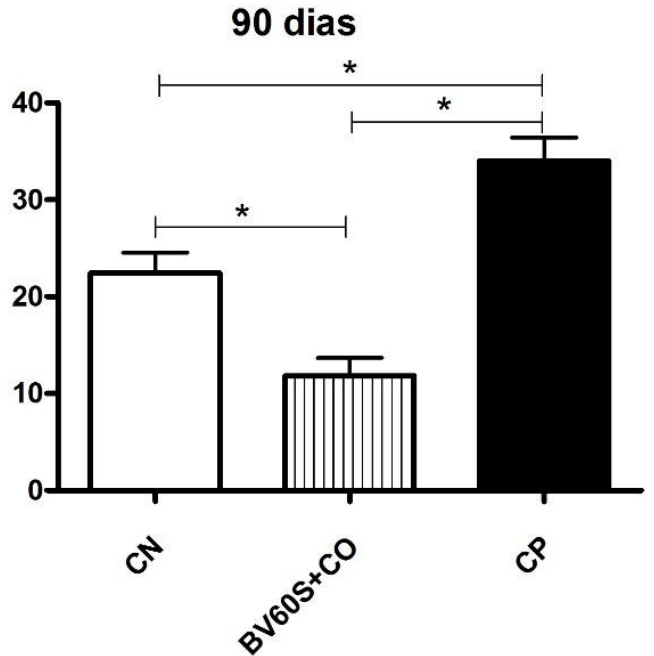

Figura 5. Percentagem média e desvio-padrão da área de neoformação óssea em defeitos críticos em rádios de cães, não tratados (C-) e tratados com matriz porosa de BV60S associada a células osteoprogenitoras (BV60S+CO), aos 45 e 90 dias de avaliação pós-operatória (medidas obtidas por histomorfometria). $*(\mathrm{P}<0,05)$.

O centro dos defeitos do grupo C- era formado por tecido conjuntivo fibroso desorganizado (Fig. 4), e do grupo (BV60S+CO) pela matriz do BV60S com tecido conjuntivo no interior dos poros e em torno da matriz (Fig. 4). Não foi observada neoformação óssea no centro dos defeitos em nenhum dos grupos C- e BV60S+CO. Também não foi observada a presença de infiltrado inflamatório em nenhum dos defeitos de todos os grupos.

\section{DISCUSSÃO}

A metodologia de estudo deve reproduzir o mais fielmente possível o problema clínico a ser tratado, razão da seleção do modelo experimental com defeitos ósseos críticos em rádio de cães. $\mathrm{O}$ maior problema da prática clínica em cães é a não união óssea em rádio de cães (DeCamp et al., 2015). A regeneração incompleta dos defeitos ósseos no grupo C- aos 90 dias (Fig. 1 e 2) mostra que o modelo experimental refere-se a defeitos críticos, caracterizados pela incapacidade de regeneração completa sem um tratamento complementar à fixação (Standard..., 2010). A completa regeneração dos defeitos ósseos observada em todos os controles positivos aos 90 dias (Fig. 1 e 2) mostra que todos os animais apresentaram capacidade de regeneração óssea normal e que a técnica de estabilização óssea foi adequada, assim como observado em outros estudos que utilizaram a mesma metodologia (Alves et al., 2015a; Alves et al., 2017a)

A maior densidade observada aos 45 dias de pósoperatório no grupo $\mathrm{BV} 60 \mathrm{~S}+\mathrm{CO}$ em relação ao grupo C- (Fig. 3) se deve à maior densidade do biomaterial em relação aos tecidos moles, uma vez que, radiográfica (Fig. 2) e histologicamente (Fig. 5), foi observada melhor área de neoformação óssea nesse grupo (BV60S+CO).

A regeneração óssea incompleta com preenchimento parcial dos defeitos observada no grupo BV60S+CO (Fig. 1, 2 e 5) mostra que esse tratamento não foi eficiente na regeneração de defeitos ósseos críticos de rádios de cães. Em 
estudo prévio com o mesmo biomaterial (BV60S), foi observada rápida reabsorção dele e sugeriu-se a associação de outras terapias capazes de estimular a regeneração óssea (Alves et al., 2015a), como o uso de células osteoprogenitoras (Alves et al., 2017a) e/ou fatores de crescimento (Levi et al., 2010; Zhu et al., 2010). Embora a associação de células osteoprogenitoras à matriz do BV60S não tenha aumentado a osteogênese no presente trabalho (Fig. 2 e 5), outros estudos obtiveram resultados mais favoráveis (Arinzeh et al., 2003; Beloti et al., 2012). A presença de células osteoprogenitoras e células-tronco capazes de se transformar em células ósseas é, provavelmente, o fator que mais contribui para o aumento da atividade osteogênica e, consequentemente, para a reparação de uma lesão óssea (Alves et al., 2017a). Uma questão ainda controversa refere-se à forma de se utilizarem as células associadas ao biomaterial. Alguns estudos recomendam a colonização in vivo (Arinzeh et al., 2003; Yuan et al., 2010), assim como o realizado no presente estudo. Nesse tipo de colonização, as células são semeadas na matriz do biomaterial e ambas são implantadas no organismo, ou seja, a colonização da matriz ocorre após sua implantação no organismo. A colonização in vivo tem a vantagem de ser uma técnica de utilização imediata, pois não é necessário o cultivo da matriz in vitro antes da implantação, possibilitando, assim, sua utilização em pacientes que necessitam de cirurgias emergenciais. Outros estudos sugerem a colonização in vitro (Belocio et al., 2012; Liu et al., 2013); nesse caso, as células são semeadas na matriz do biomaterial e cultivadas em estufa antes da sua implantação, garantindo a completa colonização da matriz antes de seu emprego. No entanto, a colonização interna de grandes matrizes in vitro é um desafio devido a problemas relacionados à semeadura e nutrição de células no centro da matriz (Silva et al., 2013).

Embora não se tenha observado nenhum indício histológico de rejeição das células osteoprogenitoras, a ineficiência na regeneração óssea observada no grupo BV60S+CO pode estar relacionada com a utilização de células alógenas, pois células estranhas ao organismo podem incitar uma resposta imunológica, prejudicando a regeneração óssea. Todavia, estudos já mostraram que as células-tronco mesenquimais alogênicas, diferenciadas ou não, possuem a capacidade de imunomodulação (Niermeyer et al., 2007) e não são rejeitadas quando implantadas em indivíduos imunologicamente compatíveis (Arinzeh et al., 2003; Mylonas et al., 2007). Estudos mostraram também sucesso com a utilização de células-tronco mesenquimais alogênicas para regeneração óssea (Arinzeh et al., 2003; Beloti et al., 2012). A utilização terapêutica de células alogênicas, assim como a realizada no presente estudo, apresenta vantagens em relação à utilização de células autógenas, pois, quando se trabalha com células alógenas, é possível a criação de bancos de células criopreservadas (Spencer et al., 2012), o que permite sua pronta utilização clínica em casos emergenciais. Além disso, podem-se selecionar doadores jovens em perfeitas condições de saúde, o que propicia o isolamento de células com alto potencial regenerativo, permitindo, assim, sua utilização terapêutica em pacientes geriátricos e com outras condições que podem afetar o potencial regenerativo das células autógenas, como a presença de doenças genéticas.

A quantidade de células utilizadas é outro fator que pode ter contribuído para o insucesso do grupo BV60S+CO. Teoricamente, quanto maior o número de células utilizado, maior será a produção de matriz e melhor será a regeneração óssea, entretanto quanto maior o número de células, maior o tempo necessário para expandilas in vitro antes da sua utilização terapêutica e, com isso, maior o tempo para se realizar o tratamento. Alguns estudos mostram sucesso com a semeadura de quantidades da ordem de $10^{6}$ células $/ \mathrm{cm}^{3}$ de defeito (Arinzeh et al., 2003; Zhu et al., 2010), assim como o utilizado no presente estudo. Outros sugerem quantidades maiores da ordem de $10^{7}$ (Yuan et al., 2010; Liu et al., 2013) e $10^{8}$ células $/ \mathrm{cm}^{3}$ para uma efetiva regeneração óssea (Wu et al., 2006).

A escolha da diferenciação osteogênica por 21 dias foi definida com base em estudos que mostram maior osteogênese in vitro nesse período (Alves et al., 2014; Alves et al., 2016). Vários outros tempos de diferenciação, como cinco (He et al., 2007), sete (Liu et al., 2013), 10 (Liao et al., 2011), 14 (Zhao et al., 2009) e 20 dias, têm sido empregados com sucesso na regeneração óssea (Boo et al., 2004). Um estudo mostrou que as células-tronco mesenquimais indiferenciadas e em estágio inicial de 
diferenciação (sete a 14 dias) são mais eficientes na regeneração óssea do que células em estágio final de diferenciação (21 dias) (Beloti et al., 2012), outro fator que pode ter contribuído para a ineficiência do grupo BV60S+CO na regeneração óssea observada no presente estudo.

\section{CONCLUSÃO}

Nas condições em que o estudo foi realizado, conclui-se que a matriz porosa do biovidro $60 \mathrm{~S}$ associada a células osteoprogenitoras é uma opção para o tratamento de defeitos ósseos críticos no rádio de cães adultos, embora menos eficiente que o autoenxerto.

\section{AGRADECIMENTOS}

Os autores agradecem à Fapemig, pelo financiamento do projeto de pesquisa; ao $\mathrm{CNPq}$, pela bolsa de estudo de doutorado; à Escola de Veterinária; ao Laboratório de Biologia Molecular do Departamento de Imunologia e Bioquímica do Instituto de Ciências Biológicas da UFMG e ao Laboratório de Densitometria da Faculdade de Medicina Veterinária da Universidade Estadual Paulista "Júlio de Mesquita Filho", pelo suporte necessário para completar o presente estudo.

\section{REFERÊNCIA}

ALVES, E.G.L.; SERAKIDES, R.; BOELONI, I.R. et al. Comparison of the osteogenic potential of mesenchymal stem cells from the bone marrow and adipose tissue of young dogs. BMC Vet. Res., v.10, p.1-9, 2014.

ALVES, E.G.L.; SERAKIDES, R.; ROSADO, I.R. et al. Porous matrix of BG60S in the treatment of critical bone defects in the radius of dogs. Arq. Bras. Med. Vet. Zootec., v.67, p.9931002, 2015a.

ALVES, E.G.L.; SERAKIDES, R.; ROSADO, I.R. et al. Effect of the ionic product of bioglass 60 s on osteoblastic activity in canines. BMC Vet. Res., v.11, p.1-8, 2015b.

ALVES, E.G.L.; SERAKIDES, R.; ROSADO, I.R. et al. Effect of ionic product of bioglass $60 \mathrm{~S}$ in osteogenic differentiation of mesenchymal stem cells from the adipose tissue of dogs. Arq. Bras. Med. Vet. Zootec., v.67, p.969-978, 2015c.
ALVES, E.G.L.; SERAKIDES, R.; BOELONI, I.R. et al. Comparative study of the osteogenic differentiation of mesenchymal stem cells from bone marrow and adipose tissue of adult dogs. Pesqui. Vet. Bras., v.36, p.21-32, 2016.

ALVES, E.G.L.; SERAKIDES, R.; ROSADO, I.R. et al. Osteoprogenitor cells can enhance early bone formation in critical bone defects in dogs. Cienc. Rural, v.47, p.1-8, 2017a.

ALVES, E.G.L.; SERAKIDES, R.; ROSADO, I.R. et al. Isolation and culture of mesenchymal stem cells derived from adipose tissue and bone marrow of dogs. Cienc. Anim. Bras., v.18, p.114, 2017b.

ARINZEH, T.L.; PETER, S.J.; ARCHAMBAULT, M.P. et al. Allogeneic mesenchymal stem cells regenerate bone in a critical-size canine segmental defect. J. Bone Joint Surg. Am., v.85, p.1927-1935, 2003.

BELOTI, M.M.; SICCHIERI, L.G.; OLIVEIRA, P.T. et al. The influence of osteoblast differentiation stage on bone formation in autogenously implanted cell-based poly(lactideco-glycolide) and calcium phosphate constructs. Tissue Eng. Part A, v.18, p.999-1005, 2012.

BOO, J.S.; YAMADA, Y.; OKAZAKI, Y. et al. Tissue-engineered bone using mesenchymal stem cells and a biodegradable scaffold. J. Craniofac. Surg., v.13, p.34-37, 2004.

COELHO, M.B.; PEREIRA, M.M. Sol-gel synthesis of bioactive glass scaffolds for tissue engineering: effect of surfactant type and concentration. J. Biomed. Mater. Res. B Appl. Biomater., v.75, p.451-456, 2005.

DeCAMP, C.E.; JOHNSTON, S.A.; DEJARDIN, L.M. et al. Brinker, Piermattei and Flo's handbook of small animal orthopedics and fracture repair. 5.ed. St. Louis: Saunders, 2015. $713 p$.

HE, Y.; ZHANG, Z.Y.; ZHU, H.G. et al. Experimental study on reconstruction of segmental mandible defects using tissue engineered bone combined bone marrow stromal cells with three-dimensional tricalcium phosphate. J. Craniofac. Surg., v.18, p.800-805, 2007. 
LEVI, B.; JAMES, A.W.; NELSON, E.R. et al. Human adipose derived stromal cells heal critical size mouse calvarial defects. Plos One., v.5, p.1$11,2010$.

LIAO, H.T.; CHEN, C.T.; CHEN, C.H. et al. Combination of guided osteogenesis with autologous platelet-rich fibrin glue and mesenchymal stem cells for mandibular reconstruction. J. Trauma, v.70, p.228-237, 2011

LIU, G.; ZHANG, Y.; LIU, B. et al. Bone regeneration in a canine model using allogeneic adipose derived stem cells and coral scaffold. Biomaterials, v.34, p.2655-2664, 2013.

MYLONAS, D.; VIDAL, M.D.; KOK, I.J.D. et al. Investigation of a thermoplastic polymeric carrier for bone tissue engineering using allogeneic mesenchymal stem cells in granular scaffolds. J. Prosthodont., v.16, p.421-430, 2007.

NIERMEYER, P.; KORNACKER, M.; MEHLHORN, A. et al. Comparison of immunological properties of bone marrow stromal cells and adipose tissue-derived stem cells before and after osteogenic differentiation in vitro. Tissue Eng., v.13, p.111-121, 2007.

SILVA, A.R.P.; PAULA, A.C.C.; ZONARI, A. et al. Development of a protocol for human adipose stem cell culture in $\mathrm{CO} 2$ independent medium and perfusion bioreactor. J. Tissue Sci. Eng., S11, 2013.
SPENCER, N.D.; CHUN, R.; VIDAL, M.A. et $a l$. In vitro expansion and differentiation of fresh and revitalized adult canine bone marrowderived and adipose tissue-derived stromal cells. Vet. J., v.191, p.231-239, 2012.

STANDARD guide for pre-clinical in vivo evaluation in critical size segmental bone defects, developed by subcommittee F04.44. ASTM F2721-09. Book of Standards, 2010. v.13.02.

WU, W.; CHEN, X.; MAO, T. et al. Bone marrow-derived osteoblast seeded into porous beta-tricalcium phosphate to repair segmental defect in canine's mandibular. Ulus Travma Acil Cerrahi Derg., v.12, p.268-276, 2006

ZHAO, J.; ZHANG, Z.; WANG, S. et al. Apatite-coated silk fibroin scaffolds to healing mandibular border defects in canines. Bone, v.45, p.517-527, 2009

YUAN, J.; ZHANG, W.J.; LIU, G. et al. Repair of canine mandibular bone defects with bone marrow stromal cells and coral. Tissue Eng. Part. A., v.16, p.1385-1394, 2010.

ZHU, L.; CHUANCHANG, D.; WEI, L. et al. Enhanced Healing of goat femur-defect using BMP7 gene-modified BMSCs and load-bearing tissue-engineered bone. J. Orthop. Res., v.28, p.412-418, 2010. 